\title{
AGRICULTURA, DESENVOLVIMENTO REGIONAL E TRANSFORMAÇÕES SOCIOESPACIAIS
}

\author{
Agriculture, regional development \\ and socio-spatial transformations \\ Agricultura, desarrollo regional \\ y transformaciones socioespaciales
}

\section{Darlene Aparecida de Oliveira Ferreira}

Doutorado em Geografia pelo IGCE-UNESP-Rio Claro. Professora do Curso de Graduação em Geografia e Pedagogia e dos Programas de Pós-graduação em Geografia e em Ciências Sociais do Instituto de Geociência e Ciências Exatas - UNESP - Universidade Estadual Paulista "Júlio de Mesquita Filho" Campus de Rio Claro. Avenida Quarenta e Oito, n.87, Jd. Primavera - Rio Claro/SP CEP 13504-056. E-mail:darlene@rc.unesp.br

\section{Rosângela Aparecida de Medeiros Hespanhol}

Pós-doutorado em Geografia pela Ecole des Hautes Etudes en Sciences Sociales do CRBC - Paris. Professora do Curso de Graduação e de Pós-graduação em Geografia da Faculdade de Ciências e Tecnologia da UNESP - Presidente Prudente. Rua Roberto Simonsen, 305 - Centro Educacional Pres.Prudente - SP CEP:19060-100. E.mail: rosangel@fct.unesp.br

\section{Giancarla Salamoni}

Pós-doutorado em Geografia - UFSM. Professora do Programa de Pós-graduação em Geografia da Universidade Federal de Pelotas-RS. Rua Marechal Deodoro, n.1400, Ap. 313-Pelotas-RS CEP 96020220.E.mail:gi.salamoni@yahho.com.br

\section{RESUMO}

O presente artigo tem como objetivo principal refletir sobre o "estado da arte" dos trabalhos apresentados no GT "Agricultura, desenvolvimento regional e transformações socioespaciais", realizado durante o XI Encontro Nacional da ANPEGE. Foram apresentados nesse GT um total de 40 trabalhos sob o formato de comunicação oral, que abordaram, sob diferentes perspectivas teórico-metodológicas e considerando realidades empíricas diversas, temas importantes que estão articulados com o escopo principal do GT, tais como a implantação de assentamentos rurais em áreas de monocultura, os efeitos socioespaciais da modernização da agricultura e a inserção de novas atividades nas unidades produtivas organizadas com base na economia familiar, industrialização da agricultura e as relações cidade-campo, a multifuncionalidade da agricultura familiar e do espaço rural, entre outros.

Palavras-chave: Agricultura. Desenvolvimento. Relações cidade-campo. Multifuncionalidade 


\begin{abstract}
This article aims to reflect upon the "state of the art" of the papers presented at the WG "Agriculture, regional development and socio-spatial transformations," held during ANPEGE's XI National Meeting. In this WG, a total of 40 papers were presented in the oral communication format, which addressed, under different theoretical and methodological perspectives and considering various empirical realities, important issues that are articulated within the main aim of the Working Group, such as the deployment of rural settlements in mono-cropping areas, the socio-spatial effects of agricultural modernization and the inclusion of new activities in productive units organized based on household economy, the industrialization of agriculture and the urban-rural relations, the multifunctionality of family farming and rural areas, among others.
\end{abstract}

Keywords: Agriculture. Development. Urban-Rural Relations. Multifunctionality

\title{
RESUMEN
}

El presente artículo tiene como objetivo principal reflejar sobre «lo último y más actual» de los trabajos presentados en el GT «Agricultura, desarrollo regional y transformaciones socioespaciales», realizado durante el XI Encuentro Nacional de ANPEGE. Se presentaron en este GT un total de 40 trabajos bajo el formato de comunicación oral, que abordaron, bajo diferentes perspectivas teórico-metodológicas y considerando realidades empíricas diversas, temas importantes que están articulados con el fin principal del GT, como la implantación de asentamientos rurales en áreas de monocultivo, los efectos socioespaciales de la modernización de la agricultura y la inserción de nuevas actividades en las unidades productivas organizadas con base en la economía familiar, industrialización de la agricultura y las relaciones ciudad-campo, la multifuncionalidad de la agricultura familiar y del espacio rural, entre otros.

Palabras clave: Agricultura. Desarrollo. Relaciones ciudad-campo. Multifuncionalidad

\section{INTRODUÇÃO}

O GT AGRICULTURA, DESENVOLVIMENTO REGIONAL E TRANSFORMAÇÕES SÓCIO ESPACIAIS teve como objetivo a troca de experiências e o fomento da discussão de resultados de investigações concluídas e em desenvolvimento sobre processos que exercem influência direta e indireta nas dinâmicas econômica, social e cultural dos espaços rurais no Brasil na atualidade. Objetivou também discutir os elementos teóricos e metodológicos das pesquisas em Geografia Agrária, analisando os conceitos e categorias geográficas sobre as temáticas que envolvem o espaço agrário.

Da análise de diferentes formas de produção (agrícolas e não agrícolas) no campo brasileiro, principalmente, após a modernização da agricultura brasileira, buscou-se uma caracterização das distintas e singulares organizações espaciais geradas pela agricultura 
familiar no território nacional. Refletiu sobre as políticas públicas, sobretudo aquelas que se direcionam à agricultura familiar, seja em escala nacional, estadual e/ou municipal, e seus efeitos sobre a agricultura e os espaços rurais, buscando garantir a segurança alimentar, a melhoria da qualidade de vida dos produtores rurais e novas oportunidades de permanência no campo, constituindo-se, na atualidade, num elemento importante para se compreender as diferenciações entre os produtores rurais e a diversidade de estratégias de reprodução socioeconômica presentes no território brasileiro.

Ao considerar o cenário nacional, regional e/ou local, as discussões propostas no âmbito do GT "Agricultura, Desenvolvimento Regional e Transformações Socioespaciais" tiveram como propósito principal problematizar as diferentes formas como os agricultores, sobretudo os de caráter familiar, seja por meio das pequenas unidades produtivas ou dos assentamentos rurais, conseguem permanecer produzindo na agricultura e se reproduzindo socialmente no espaço rural, apesar das limitações apresentadas pelas ações pontuais do Estado brasileiro, sobretudo em relação ao crédito rural e à assistência técnica, e da expansão do agronegócio sobre as áreas de produção alimentar.

As apresentações dos trabalhos propiciaram uma visão geral sobre os diferentes temas e espaços enfocados a partir de estudos de caso. A opção metodológica da maior parte dos trabalhos apresentados no GT pelo estudo de caso se deve pelo fato de propiciar uma imagem mais completa e real dos fatos que caracterizam o problema pesquisado, representando uma estratégia muito utilizada quando se levantam questões do tipo "como" e "por que", sendo que o pesquisador tem pouco controle sobre os eventos e quando o foco se encontra em fenômenos contemporâneos inseridos em algum contexto da vida real (YIN, 2001).

Foi possível constatar que os problemas derivados do modelo de desenvolvimento (rural, local, regional, etc.) adotado pelo país, com base na modernização das atividades agropecuárias, agravaram os problemas sociais, ambientais, econômicos e políticos.

Essa perspectiva converge para o reconhecimento "de que a produção em grande escala, vinculada ao abastecimento de mercados globais, estaria levando a uma redução nos índices de emprego e renda e a uma pequena diversificação das atividades econômicas em seu entorno." (NORDER, 2006, p. 58)

As características específicas de cada território e sociedade local/ regional, bem como as distintas trajetórias (econômicas, sociais, políticas e culturais), em relação à forma como se deu a formação socioespacial e a inserção na divisão do trabalho, possibilitam o reconhecimento de pelo menos um ponto em comum entre as realidades apresentadas pelos trabalhos no GT: os efeitos perversos das transformações ocorridas na agricultura sobre os agricultores e suas famílias. 
O processo de reprodução do capital, viabilizado pela integração agricultura/indústria, nem sempre está de acordo com os objetivos de desenvolvimento dos produtores rurais e de suas famílias. Os agricultores sofrem o impacto de mudanças radicais, ao terem o seu processo produtivo submetido ao processo de industrialização. Essas circunstâncias justificam a forma de pensar a agricultura subordinada ao capital industrial, tanto em nível nacional como internacional.

A análise de trinta anos de evolução do mundo rural, anterior aos anos 1980, efetuada pela Comunidade Europeia aponta a profunda reestruturação pela qual passou o setor agrário, indicando para

\begin{abstract}
disminución de la superficie de uso agrario (sobre todo entre I960 y 1975), fuerte reducción de la mano de obra, modernización e intensificación de los procesos de producción y cierta tendencia a la polarización estructural; aumenta la parte de superfície agraria y producción correspondiente a explotaciones de más de 50 hectáreas, pero subsisten un gran número de pequeñas explotaciones, bien a tiempo parcial (con otras actividades lucrativas), o bien como explotaciones en situación de bloqueo estructural con un importante subempieo (desempleo lantente, desempleo encubierto); cada uma de estas dos últimas categorías representa aproximadamente un tercio de las explotaciones comunitárias. (COMISIÓN COMUNIDADES EUROPEAS, 1988, p. 5)
\end{abstract}

As mudanças tecnológicas surgidas após a Segunda Guerra Mundial e incorporadas ao processo produtivo de alguns segmentos da agricultura redundaram no aprofundamento dos processos de urbanização e de industrialização, os quais foram acompanhados de intensos fluxos migratórios em direção às cidades, empobrecimento nas áreas rurais periféricas, entre outros problemas.

Na perspectiva de Santos (2000), o aprofundamento das técnicas e a sua difusão nos diferentes espaços revelam cada vez mais a capacidade do homem em se apropriar, modificar e reduzir a dependência da sociedade em relação às condições naturais. Deste modo, como enfatiza o autor:

Os últimos séculos marcam, para a atividade agrícola com a humanização e a mecanização do espaço geográfico, uma considerável mudança de qualidade, chegando-se recentemente, à constituição de um meio geográfico a que podemos chamar de meio técnico-científicoinformacional, característico não apenas da vida urbana, mas também do mundo rural, tanto nos países avançados como nas regiões mais desenvolvidas dos países pobres. (SANTOS, 2000, p.88).

Dessa forma, ao mesmo tempo em que esse processo de modernização ampliou a subordinação da agricultura - aprendida apenas como um setor econômico -, ela favoreceu os interesses dos capitais urbano-industriais e excluiu um grande número de produtores rurais estruturado sob a economia familiar. 
É importante ressaltar que o aprofundamento do capitalismo no campo no país a partir dos anos 1960, com o processo de modernização da agricultura, e a reestruturação produtiva da a agricultura nos anos 1980/90 exerceram forte influência, direta e indireta, nas dinâmicas econômica, social e cultural dos espaços rurais e na forma de produção dos agricultores e de sua inserção nos mercados.

Por isso, as transformações socioespaciais ocorridas na agricultura, desde meados dos anos 1960, ganham magnitudes tais, que impõem uma revisão dos marcos teóricos utilizados na análise do desempenho das atividades dos vários segmentos que conformam a economia brasileira. A necessidade de tal procedimento justifica-se, vis-à-vis à existência de um processo tecnoeconômico e sociopolítico que solapou as bases tradicionais da agricultura, em alguns casos fragilizando a reprodução social e territorial das formas familiares, a ponto de esta ser induzida a adotar os veículos de integração (crédito, maquinaria, insumos industriais, entre outros), como condição de sobrevivência dentro do contexto dos novos padrões produtivos presentes no rural.

Os graves impactos ambientais provocados pela agricultura moderna podem ser entendidos como o rompimento da estabilidade dos ecossistemas e a consequente redução da sustentabilidade do próprio desenvolvimento econômico e social. Ainda que certos graus de artificialização e homogeneização sejam imanentes a quase toda a atividade econômica, a tecnificação da agricultura tem mostrado uma total falta de limites na agressão ao meio ambiente, comprometendo, ao longo do tempo, a reprodução da sociedade como um todo e, mais especificamente, dos agricultores familiares.

A diversidade de situações empíricas apresentadas nos trabalhos do GT reforça a própria capacidade de persistência e de adaptação dos produtores rurais em contextos sociais, econômicos, políticos e ambientais diferenciados, levando-os a adotarem diferentes estratégias de reprodução econômica e social para garantirem a manutenção da família e da sua cultura.

A permanência dessas unidades produtivas organizadas com base no trabalho familiar no meio rural pode ser explicada na própria lógica de desenvolvimento desigual, contraditório e combinado do modo de produção capitalista. Isso porque ao mesmo tempo em que o capital busca a exploração e a subordinação da produção familiar rural, esta, por sua vez, resiste no campo, como forma de garantir a manutenção da família ou de parte de seus membros.

Essa capacidade de resistência dos produtores no campo está vinculada às estratégias adotadas e/ou desenvolvidas, podendo ser interpretadas como o resultado das escolhas, 
opções e decisões dos indivíduos em relação à família e da família em relação ao indivíduo, envolvendo fatores sociais, econômicos, étnico-culturais e espaciais.

Dessa forma, como observa Schneider (1999, p.135)

(...) embora se tratem de estratégias conscientes e racionais, essa consciência é mediatizada por uma racionalidade informada pela realidade que tanto é expressão das relações materiais presentes como daquelas herdadas de seu passado e transmitidas culturalmente. Desse modo, as estratégias não são causais ou teleológicas, mas resultado da ação humana frente às contingências e situações objetivas.

De acordo com Brumer et. al. apud Lamarche (1998), as estratégias adotadas pelas famílias rurais variam de uma região a outra e de uma unidade produtiva a outra. Isso porque, a diversidade das lógicas produtivas e as adversidades climáticas e econômicas acarretam a busca de alternativas distintas para a reprodução econômica das famílias.

Assim, as transformações ocorridas no meio rural brasileiro nos últimos anos, têm propiciado a realização de várias pesquisas no país que procuram compreender os efeitos socioespaciais desses processos sobre os agricultores e as mudanças que ocorrem nos espaços rurais, resultando em análises que enfocam a diversidade e heterogeneidade da agricultura e dos espaços rurais no país.

A partir dos trabalhos apresentados, que tem diferentes recortes espaciais e temporais, além de procedimentos metodológicos diversificados, foram selecionados aqueles textos que versam sobre o tema principal do GT e que serão apresentados na próxima seção do artigo.

\section{A DIVERSIDADE DE FORMAS DA AGRICULTURA NO ESPAÇO AGRÁRIO BRASILEIRO}

Verificou-se, a partir da apresentação dos trabalhos, que as transformações socioespaciais são analisadas a partir de algumas vertentes de análise, tais como a inserção de assentamentos rurais em áreas em que a monocultura da cana de açúcar é predominante, embora se apresente em declínio, como se constatou no trabalho intitulado "O RURAL NO NORTE FLUMINENSE"; da introdução de novas atividades produtivas, como a soja, a cana de açúcar e o milho que podem colocar em risco atividades tradicionalmente realizadas pelos agricultores familiares, no Triângulo Mineiro, como o abacaxi, processo destacado no trabalho “(RE)EXISTÊNCIA DOS AGRICULTORES FAMILIARES”; a (re)organização da produção artesanal em virtude da introdução de novas bases tecnológicas e de normas, como é o caso do queijo do Marajó, como destacado no texto "A AGRICULTURA CAMPONESA NO MARAJÓ: ENTRE O LATIFÚNDIO TRADICIONAL E O MODERNO"; da reestruturação produtiva resultante da introdução da técnica, da ciência e da informação, como no trabalho "A NOVA GEOGRAFIA DA PRODUÇÃO DE COCO NO BRASIL"; e da 
modernização da agricultura que provou (e ainda provoca) profundas transformações na agricultura familiar, como destacado no trabalho "DO SISTEMA AGRÁRIO COLONIAL AO SISTEMA AGRÁRIO MODERNO: TRANSFORMAÇÕES SÓCIO ESPACIAIS NA AGRICULTURA FAMILIAR EM LAJEADO-RS”.

De acordo com o exposto nos estudos apresentados, muitas das unidades produtivas familiares foram, ao longo do processo de modernização da agricultura, incorporando técnicas e sistemas de produção inadequados à disponibilidade de mão de obra, ao tamanho das propriedades, à capacidade financeira e às condições ecológicas em que estas se encontram. Observa-se que a produção familiar convive com o capital ao entrar no mercado e estar subordinada às determinações deste. Na maioria das vezes, o grupo familiar produz de acordo com o interesse de grupos empresariais que necessitam de seus produtos e de sua força de trabalho para realizar a complexa circulação do capital.

Quando se analisa o processo de integração dos produtores familiares às agroindústrias, é importante desvendar as relações pelas quais acontece a submissão do produtor ao capital industrial e comercial. Muitas vezes, a articulação entre agricultura e indústria chega a subverter os elementos que constituem a organização interna das unidades familiares: o "balanço trabalho / consumo", como fator determinante das decisões econômicas do produtor familiar, cede lugar para as determinações impostas pelo setor urbano-industrial. A compreensão desse processo e as contradições que dele emergem são condições necessárias para se pensarem propostas de desenvolvimento voltadas à agricultura familiar.

As relações entre campo e cidade são discutidas a partir da industrialização da agricultura e seus impactos nas pequenas cidades do interior do país, como se verifica no trabalho "INDUSTRIALIZAÇÃO DA AGRICULTURA E TERRITORIALIZAÇÃO DO CAPITAL: TRANSFORMAÇÕES RECENTES NA RELAÇÃO CAMPO-CIDADE EM CAARAPÓ - MATO GROSSO DO SUL - BRASIL"; a partir da expansão do agronegócio, como a soja no Mato Grosso, e os impactos econômicos e sociais resultantes para essas áreas, como ressaltado pelo trabalho "AS RECENTES TRANSFORMAÇÕES SÓCIO ESPACIAIS DO NOROESTE MATO-GROSSENSE"; ou a partir das mudanças ocorridas na agropecuária regional, com a decadência da cafeicultura e a expansão da cana de açúcar em pequenas localidades no interior do Estado de São Paulo, como tratado em “DISTRITOS MUNICIPAIS, AGROPECUÁRIA E POLÍTICAS PÚBLICAS: UM ESTUDO GEOGRÁFICO DOS DISTRITOS JAMAICA E JACIPORÃ/DRACENA-SP”. Nesses pequenos lugares, apreendidos como possibilidade de residência, conforme constatado pela autora, as políticas públicas adquirem fundamental importância para a permanência das famílias nos espaços de convívio cotidiano. 
Esses estudos, cuja inflexão converge para as relações cidade-campo, conferem aos processos de industrialização a causa das mudanças nas formas e funções das pequenas cidades, tanto em termos físicos (infraestrutura, logística, bens e serviços urbanos), quanto humanos (alterações nas relações sociais e modos de vida). Por outro lado, a inserção de novas estruturas produtivas no campo, ocasiona intensas transformações espaciais na escala local e regional. Uma vez que para sua implantação necessita de toda uma infraestrutura de armazenamento e transporte, redes viária, informacional e financeira eficientes, fornecedores de insumos e componentes agrícolas, além de uma efetiva rede de contato com mercados consumidores. Segundo apontam as pesquisas, as transformações resultantes desse processo, imperadas sobre o espaço geográfico, agem como ajustes espaço-temporais necessários à reprodução do sistema capitalista vigente.

A relevância que as políticas públicas adquirem no contexto atual para os agricultores familiares, sobretudo relacionadas ao crédito rural, ao Programa de Aquisição de Alimentação (PAA) e o Programa Nacional de Alimentação Escolar (PNAE), foi discutida no trabalho "AS TRANSFORMAÇÕES SÓCIO ESPACIAIS NO SISTEMA AGRÁRIO FAMILIAR DE PELOTAS/RS: A AÇÃO DAS POLÍTICAS PÚBLICAS NA VALORIZAÇÃO DA MULTIFUNCIONALIDADE”. No trabalho, a autora apresenta um panorama sobre a atuação das políticas públicas no processo de "transformações socioespaciais ocorridas, ao longo do tempo, no sistema agrário familiar do município de Pelotas/RS” (p. 2744). Ao caracterizar a agricultura familiar do município de Pelotas, ela destaca que essas unidades produtivas apresentam uma "policultura combinada com a pecuária leiteira, esta última voltada para o consumo da família ou para a produção semiespecializada para o mercado, em situações de integração dos produtores com as cooperativas de leite e derivados" (p. 2752). Na avaliação da autora, "a partir da análise do sistema agrário familiar de Pelotas foi possível identificar diretrizes capazes de nortear a elaboração de políticas públicas voltadas para o desenvolvimento rural. Nesse sentido, o objetivo de cada unidade de produção deve consistir na elevação da produtividade e da qualidade dos produtos gerados, desde que mantendo o equilíbrio dinâmico dos ecossistemas locais”. (p. 2752)

Resta enfatizar que não obstante o fato de que os programas analisados busquem fomentar determinados processos fundamentais para o desenvolvimento rural - e obtenham sucesso nesse intuito -, não se pode imaginar que os mercados institucionais, sozinhos, possam resolver problemas estruturais do rural. Nesse sentido, considerandose o caso brasileiro, em que as políticas públicas ainda se restringem, fundamentalmente, ao âmbito da atividade agrícola, o PAA e o PNAE têm prestado, dentro de seus próprios limites, uma contribuição muito significativa. Apesar de apresentar problemas, 
esses programas promoveram avanços importantes nos espaços rurais brasileiros. Verdadeiramente, não foram capazes de resolver em menos de duas décadas problemas estruturais perpetrados ao longo dos séculos, mas foram essenciais para a reprodução social dos seus muitos beneficiários.

Relacionada à expansão do agronegócio no país, mais especificamente no Estado de São Paulo, e as alternativas criadas pela agricultura familiar em diferentes momentos históricos, para permanecer se reproduzindo no campo, foi o tema abordado em "AS SUCESSIVAS EXPANSÕES DAS MONOCULTURAS DE CAFÉ, LARANJA E CANA-DE-AÇÚCAR DO MUNICÍPIO DE TABAPUÃ/SP E A RESISTÊNCIA DA AGRICULTURA FAMILIAR". Segundo os autores, esses três cultivos foram selecionados uma vez que geraram para o município prestígio, riqueza, mas, de forma contraditória, forçou a agricultura familiar a desenvolver formas de resistência a fim de oportunizar aos agricultores meios de recursos para manter suas atividades, garantindo sua permanência no campo.

Percebe-se que as forças exercidas pelas monoculturas, especialmente a cana de açúcar, vêm se expandindo em áreas anteriormente dedicadas às culturas alimentares. $\mathrm{O}$ avanço sobre as terras da agricultura familiar, devido sua forte valorização no mercado e a instalação de usinas na região, causa um aumento no êxodo rural e força o agricultor a buscar alternativas para resistir no campo. A produção de cana-de-açúcar na atualidade se volta, sobretudo, em atender as metas diretamente ligadas ao açúcar (mercado interno e externo) e ao álcool combustível (mercado interno). O agricultor se encontra pressionado pelo grande capital e acaba arrendando suas terras para as usinas, e se deslocando para a cidade. Os que persistem, e submetem-se ao arrendamento, utilizam seus poucos hectares, ou o que resta próximo as suas residências, para cultivar hortaliças ou frutas (como o limão, a manga e a tangerina, por exemplo) para o consumo próprio ou mesmo para atender o mercado local e/ou regional. No entanto, há agricultores que buscam alternativas como, por exemplo, a seringueira (investimento a longo prazo por se tratar de um cultivo permanente, a mesma não é uma exploração recente na área de estudo, porém há evidência de que esse cultivo possa se tornar uma nova expansão de monocultura). (p. 3050)

Associada à diversidade da agricultura familiar, o trabalho "MUDANÇAS DO USO E DA OCUPAÇÃO DO SOLO - DINÂMICAS POPULACIONAIS DE ABANDONO DO CAMPO - ESPERANÇA DO SUL/RS”, enfoca o processo de formação territorial do município pelos imigrantes alemães e como a modernização da agricultura a partir dos anos 1960, provocou uma intensa migração campo-cidade dos trabalhadores rurais e degradação ambiental. Na atualidade, segundo os autores do trabalho, o envelhecimento da população que permaneceu na zona rural do município e "o abandono de algumas parcelas 
das propriedades e diminuição da área utilizada pela lavoura, principalmente, aquelas que estão localizadas em áreas de relevos íngremes" (p.3026), tem possibilitado constatar a "mudança no uso e na ocupação do solo, com a regeneração de mata nativa”. (p. 3026-3027)

O estudo de comunidades, a partir das continuidades e rupturas ocorridas no período mais recente (anos 1990), foi o eixo estruturante do trabalho "MUDANÇAS E PERMANÊNCIAS NO ESPAÇO RURAL DA COMUNIDADE DE SANGRADOURO, ARARANGUÁ-SC (1990-2015)”. A inserção de “atividades não agrícolas na comunidade em questão, bem como o reconhecimento estatal do agricultor familiar, por meio de políticas públicas específicas para o segmento” (p. 3002) foram as problemáticas abordadas no trabalho. Segundo os autores, "a manutenção das unidades produtivas pelos camponeses, em sua estrutura, bem como as relações estabelecidas entre eles com a terra, a vizinhança, e os novos empreendimentos não agrícolas, fundamentam a compreensão das continuidades em Sangradouro, enquanto a pluriatividade e a sucessão geracional são temáticas centrais para a compreensão das rupturas”. (p. 3003)

O desenvolvimento rural e as politicas públicas foi outro eixo importante no grupo de trabalho. No trabalho "DESENVOLVIMENTO RURAL NO BRASIL E NO NORTE DE MINAS: BREVES CONSIDERAÇÕES”, os autores procuram discutir o desenvolvimento rural no Brasil e, de maneira mais particularizada no Norte de Minas, tendo como recorte temporal o período compreendido entre o século XX e início do século XXI. O processo de modernização da agricultura e as dificuldades dos pequenos produtores rurais para se inserirem nessa nova dinâmica, em que foram privilegiados os grandes produtores rurais voltados ao mercado externo, e no mercado de forma competitiva(p. 2997) são alguns dos aspectos discutidos neste trabalho. Ao enfocar os efeitos do processo de modernização da agricultura no norte de Minas Gerais, a exclusão social dos pequenos produtores rurais e a concentração fundiária foram intensificados, como verificados pelos autores do trabalho.

Discutindo as politicas públicas, na perspectiva do território, o trabalho intitulado "NOVOS RUMOS DO PLANEJAMENTO REGIONAL: a (re)significância do conceito território", procura compreender o Programa Territórios da Cidadania, tendo como recorte espacial o Agreste Central Pernambucano, em que "por meio de ações de valorização e atuação dos atores do território, [...] vem contanto com a participação da sociedade e se de fato vem contribuindo para o desenvolvimento socioeconômico regional”. (p. 2980). Apesar de não apresentar muitos resultados empíricos, o trabalho realiza uma discussão interessante sobre o conceito de território e sua aplicação nas politicas públicas.

As atividades agropecuárias, as transformações que estas tiveram com a modernização da agricultura e sua importância no desenvolvimento regional foi o tema do trabalho 


\section{“A PECUÁRIA BOVINA NA MICRORREGIÃO GEOGRÁFICA DA CAMPANHA} MERIDIONAL: PERSPECTIVAS DE DESENVOLVIMENTO REGIONAL”. Neste trabalho, apesar da pecuária bovina na escala regional, se constituir num "importante segmento produtivo, sendo desenvolvida em algumas propriedades de modo extensivo [...] observa-se a inserção de novas técnicas no processo produtivo, desde a inseminação ao abate e na comercialização, buscando-se a criação de novos nichos de mercado. Ressalta-se que esta atividade encontra-se em um excelente período econômico e conta com a identificação da população regional, a qual viria a contribuir tanto para pequenos, quanto para médios e grandes produtores rurais". (p. 2935). Com a perspectiva também de analisar a pecuária leiteira e as transformações pelas quais essa atividade vem passando na escala municipal, no período 1960/2013, com a implantação de unidades processadoras e seus efeitos socioespaciais, o trabalho "A PECUÁRIA LEITEIRA EM ITUIUTABA/ MG: PERSPECTIVAS E ENTRAVES NO DESENVOLVIMENTO SOCIO ESPACIAL DO MUNICÍPIO", destacando o Cerrado e conectando à realidade visualizada em Ituiutaba, reafirma que a produção agropecuária e o setor agroindustrial são fundamentais na configuração das transformações sócio espaciais do município estudado. Neste panorama, a problemática da investigação verificou a importância da produção de leite, como uma cadeia produtiva responsável pela organização/reorganização espacial local/regional frente à expansão das culturas comerciais, como a soja e a cana de açúcar. E, ao apresentar os principais processos que viabilizam o desenvolvimento do setor leiteiro, verificando os entraves e as perspectivas de evolução ou estagnação na dinâmica produtiva agropecuária e agroindustrial deste município, aponta a relevância que o setor produtivo lácteo possui na escala local.

\section{AS TRANSFORMAÇÕES SOCIOESPACIAIS NA AGRICULTURA: UMA TENTATIVA DE SÍNTESE}

Como já apontamos, o GT teve o objetivo de propiciar a troca de experiências e fomentar a discussão dos resultados de investigações em torno do tema da agricultura, desenvolvimento e transformações socioespaciais, refletindo sobre processos que exercem influência direta e indireta nas dinâmicas econômica, social e cultural dos espaços rurais. Na perspectiva de Kageyama (2008, p.11) "a complexidade e a multidimensionalidade do desenvolvimento se associam, portanto, à heterogeneidade imposta pelas dotações geográficas e pela ocupação e evolução histórica do território." 
Cazella, Bonnal; Maluf (2009) complementam essa visão quando afirmam que:

\begin{abstract}
No transcurso da última década, a noção de território assumiu importância destacada nos discursos dos gestores de políticas públicas de numerosos países, inclusive o Brasil. No que diz respeito à agricultura e ao meio rural, o território aparece cada vez mais como uma entrada programática, inovadora e privilegiada para renovar a concepção de desenvolvimento rural. (CAZELLA; BONNAL; MALUF, 2009, p. 25)
\end{abstract}

Analisando as diferentes formas de produção (agrícolas e não agrícolas) no campo brasileiro, principalmente, após a modernização da agricultura brasileira e o processo de reestruturação produtiva, buscou identificar as distintas e singulares organizações espaciais geradas pela agricultura familiar no território nacional. Ao refletir sobre as políticas públicas, sobretudo aquelas que se direcionam à agricultura familiar, seja em escala nacional, estadual e/ou municipal, e seus efeitos sobre a agricultura e os espaços rurais, percebeuse que estas se constituem, na atualidade, num elemento importante para se compreender as diferenciações entre os produtores rurais e a diversidade de estratégias de reprodução socioeconômica presentes no território brasileiro.

A partir da reflexão sobre as transformações promovidas no espaço brasileiro pela modernização da agricultura, inaugurada no país nas décadas de 1950-60, é possível repensar as relações entre este processo, o desenvolvimento e a produção familiar rural. Entendese que, como a produção familiar tem demonstrado uma surpreendente capacidade de adaptação às diversas mudanças que ocorreram ao longo da história econômica e política do País, é a partir dela que poderão ser implementadas alternativas de desenvolvimento para os espaços rurais. Para isso, tornam-se imprescindíveis investimentos em novas estruturas de produção e de comercialização, incluindo a importância dos mercados institucionais, pesquisas direcionadas às necessidades e condições do produtor familiar, além de políticas que viabilizem a geração e difusão de novas tecnologias adaptadas às condições dessa categoria de produtores e a capacidade de investimento dos agricultores. Sem esquecer a dimensão ambiental dos agroecossistemas.

Por outro lado, ficou evidente que nas áreas de expansão dos monocultivos, particularmente aqueles voltados para a exportação, quase não existe a mobilidade de recursos econômicos e articulação social que possam engendrar outras possibilidades de desenvolvimento para a agricultura familiar. Essa constatação evidencia que a reduzida diversificação em certos territórios deve-se a dominância da produção especializada em grande escala, a qual desarticula ou torna fragilizadas as formas da agricultura familiar. Esta última, responsável por sistemas poliprodutivos que garantem os níveis de emprego e renda no campo. 
Para Norder (2006), no contexto da agricultura familiar e dos assentamentos rurais no Brasil, as práticas produtivas e as estratégias sociais apresentam entre suas características:
a) a intensificação na absorção de força de trabalho e na geração de renda por unidade de área (em comparação aos principais índices vigentes na produção em grande escala);b) a utilização de força de trabalho na constituição de instrumentos de trabalho;c)a ampliação contínua no montante de recursos permanentes disponíveis na propriedade(máquinas, implementos ferramentas,instalações,construções, sistemas de criação animal, cultivos permanentes, etc.);d)a busca por uma redução sistemática no montante e na proporção de insumos de curto ciclo adquiridos no mercado para se alcançar um certo volume de produção;e)a adequação e o aprimoramento no uso dos recursos naturais disponíveis. (NORDER, 2006, p.65-66)

Nessa perspectiva, o Estado passa a ter papel fundamental, deflagrando a anunciada "prioridade à agricultura familiar", a partir de meados dos anos 1990 e no decorrer dos anos 2000. Esse aspecto conjuntural permanece equivocado quanto ao tratamento discriminado presente nas políticas públicas voltadas ao desenvolvimento rural e demonstra que as proclamadas prioridades agrícolas dispensadas aos produtores e às suas atividades, foram mais aparentes do que reais. Tanto no que se refere a medidas mais específicas, como o crédito, quanto às políticas de caráter mais geral, como o apoio seletivo definido na intervenção estatal reflete os objetivos dos grupos mais capitalizados na política de seleção de produtos, produtores e regiões, a serem utilizados como suporte na reprodução contínua do padrão de acumulação capitalista.

De forma complementar a atuação do Estado, cumpre trazer para a discussão que as estratégias de desenvolvimento também se encontram ancoradas nos processos participativos dos próprios atores sociais. No entanto, essa é uma dimensão que traz a tona as assimetrias na configuração da sociedade e de suas capacidades e possibilidades reivindicatórias. De acordo com Silva e Marques (2009, p.18, grifos dos autores) "percebe-se a grande fragilidade dos atores sociais no sentido de constituir em canais de absorção, processamento e expressão de interesses e demandas difusas do 'mundo da vida'(neste caso, particularmente, dos agricultores familiares) ganhando assim reconhecimento e sustentação social."

Por fim, outro desafio proposto para reflexão crítica foi o de compreender as relações campo-cidade a partir da afirmação da complementaridade destas duas formas espaciais de vida social. Emergiu, assim, os conceitos de pequena cidade e suas relações produtivas, econômicas e sociais pelo viés da relação campo-cidade, modificadas pela industrialização da agricultura, com referência na transição de povoado numa economia do excedente para o contexto de cidade numa economia de mercado com base na propriedade privada da terra. Para Wanderley (2009), a presença do mundo rural pode ser percebida tanto pelos indicadores socioeconômicos e demográficos, quanto pelo fato de que o urbano dos chamados "pequenos municípios" está impregnado pelas qualidades do rural. Para a 
autora, nos pequenos municípios, "tanto a trama espacial e social, como as trajetórias de desenvolvimento são preponderantemente rurais."(WANDERLEY, 2009, p.327)

\section{CONCLUSÕES}

Em geral, os estudos sobre o urbano e rural passam por uma crise axiológica, fruto de visões reducionistas sobre a realidade. Também, possivelmente pelos mesmos motivos, passam por uma grave crise ética que consiste em um perverso desprezo pelo futuro das gerações vindouras. Entretanto, o que foi observado no conjunto de trabalhos reunidos pelo GT “Agricultura, Desenvolvimento Regional e Transformações Socioespaciais” foi o reconhecimento de inúmeros processos, nos quais práticas e saberes podem se constituir em estratégias de reprodução social e econômica, relacionadas diretamente com a diversidade dos territórios rurais. Ao discutir os elementos teóricos e metodológicos das pesquisas em geografia agrária, analisando os conceitos e categorias geográficas sobre as temáticas que envolvem os espaços rural e urbano, a partir da organização espacial, verifica-se que a noção interdisciplinar de multifuncionalidade pode contribuir nas análises do espaço rural, tendo em vista a gestão do território, em diferentes contextos histórico-espaciais.

A agricultura familiar também foi o foco dos estudos relacionados com as estratégias adotadas por este segmento para se organizar e reorganizar diante das especificidades do desenvolvimento do modo de produção capitalista. Muitos trabalhos apresentados no GT foram produzidos visando aprofundar o conhecimento acerca da produção familiar na agricultura, especulando sobre o seu destino e as formas como este segmento se desenvolve pari passu ao sistema capitalista contemporâneo, enfatizando os processos de adaptação ao sistema de mercado.

Ainda, foram discutidos os graves impactos ambientais provocados pela agricultura moderna, entendidos como o rompimento da estabilidade dos ecossistemas e a consequente redução da sustentabilidade do próprio desenvolvimento econômico e social. Ainda que certos graus de artificialização e homogeneização sejam imanentes a quase toda a atividade econômica, a tecnificação da agricultura tem mostrado uma total falta de limites na agressão ao meio ambiente comprometendo, ao longo do tempo, a reprodução da sociedade como um todo e, mais especificamente, dos produtores rurais.

Os processos agrários históricos indicam que a chamada modernização da agricultura promoveu profundas modificações nas estruturas socioambientais, bem como, nas consagradas e sustentáveis práticas aplicadas aos sistemas de produção familiares. Com a 
drástica diminuição da agrobiodiversidade nos sistemas agrícolas familiares percebe-se uma nociva alteração nutricional das comunidades rurais e da população com um todo, uma vez que isso ocorre a partir da diminuição na oferta de alimentos. Este quadro diminui o teor de endogeneidade dos agroecossistemas, rompendo com a autonomia no processo de reprodução cultural e alimentar do agricultor familiar. Por outro lado, foram identificadas pelos autores diversas formas de reprodução socioeconômica da agricultura familiar frente à expansão do agronegócio, as quais estabelecem as condições de permanência no campo. Bem como, a manutenção da diversidade produtiva, abrangendo a produção para o autoconsumo e para a comercialização, foi apresentada como forma de resistência a dominância dos monocultivos.

Cabe ressaltar que a agricultura familiar tem grande potencial para promover o desenvolvimento rural, não somente por ser responsável pelo fortalecimento de sistemas de produção diversificados, mas por ser detentora de um patrimônio cultural que lhe confere um caráter particular de organização interna. De um lado, o domínio do uso de insumos e técnicas e, de outro, os conhecimentos empíricos de gestão que ultrapassam a esfera dos cultivos e orientam o funcionamento da unidade de produção como um todo. Pode-se dizer que a racionalidade camponesa constitui uma das estratégias de reprodução do produtor familiar, frente ao processo de expansão capitalista.

É extremamente importante não permitir que a valorização da lógica mercantil capitalista provoque danos ao tecido co-evolutivo socioambiental das comunidades rurais. Ao reconhecer a riqueza da sociodiversidade e a biodiversidade, as políticas públicas de gestão territorial dos espaços rurais devem valorizar essa vantagem comparativa na elaboração de programas voltados para a agricultura. Assim procedendo, os gestores públicos estarão promovendo a almejada sustentabilidade e autonomia local, bem como salvaguardam a soberania e segurança alimentar nos espaços rurais e urbanos do país.

Diante disso, o rural passa por uma renovação de princípios norteadores, tanto do ponto de vista conceitual, quanto de políticas públicas (GRAZIANO DA SILVA, 1999). Assim, se verifica uma busca por um chamado desenvolvimento do rural e não um desenvolvimento agrícola (modernização da agricultura). Nesse sentido, o enfoque territorial passou a ser um instrumento fundamental das políticas públicas, retirando a proeminência das questões setoriais nas discussões sobre o desenvolvimento econômico e social. Outro elemento conceitual que surge no bojo destas transformações, vinculado com o enfoque espacial, é a noção de multifuncionalidade da agricultura familiar que representa, também, um esforço de rompimento com a ótica setorial e enfatiza, principalmente, a heterogeneidade estrutural presente no rural. 
Finalmente, esse conjunto de reflexões sugeridas pelos trabalhos apresentados no GT, sustentados, em sua maioria, em estudos de caso, leva a concluir que a produção do conhecimento sobre o espaço agrário brasileiro precisa estar em contínuo processo de atualização. Só assim é possível compreender a complexidade que as situações reais têm imposto à teoria geográfica.

\section{REFERÊNCIAS}

1. ALVES, Aline Turatti; CHELOTTI, Marcelo Cervo. Mudanças e permanências no espaço rural da Comunidade de Sangradouro, Araranguá-SC (1990-2015). XI ENANPEGE, 2015, Pres. Prudente. Anais... Pres. Prudente: ENANPEGE, p. 2828-2839, 2015. Disponível em: www. enanpege.ggf.br/2015 (p. 3002-3011).

2. ALVES, Ana Luiza Pinto BEZZI, Meri Lourdes. A pecuária bovina na Microrregião Geográfica da Campanha Meridional: perspectivas de desenvolvimento regional. XI ENANPEGE, 2015, Pres. Prudente. Anais... Pres. Prudente: ENANPEGE, p. 2828-2839, 2015. Disponível em: www.enanpege.ggf.br/2015 (p. 2933-2944).

3. ANDRADE, Gevson da Silva Andrade; MACHADO, Maria Rita Ivo de Melo; DANTAS, Francisco das Chagas. Novos rumos do planejamento regional: a (re)significância do conceito território. XI ENANPEGE, 2015, Pres. Prudente. Anais... Pres. Prudente: ENANPEGE, p. 28282839, 2015. Disponível em: www.enanpege.ggf.br/2015 (p. 2972-2992).

4. ANTUNES, Maryna Vieira Martins. Distritos municipais, agropecuária e políticas públicas: um estudo geográfico dos Distritos Jamaica e Jaciporã/Dracena-SP. XI ENANPEGE, 2015, Pres. Prudente. Anais... Pres. Prudente: ENANPEGE, p. 2828-2839, 2015. Disponível em: www.enanpege.ggf.br/2015 (p. 2805-2816).

5. CANEPPELE, Jean Carlo Gessi; VERDUM, Roberto. Mudanças do uso e da ocupação do solo - dinâmicas populacionais de abandono do campo - Esperança do Sul/RS. XI ENANPEGE, 2015, Pres. Prudente. Anais... Pres. Prudente: ENANPEGE, p. 2828-2839, 2015. Disponível em: www.enanpege.ggf.br/2015 (p. 3025-3036).

6. CAVALCANTE, Leandro Vieira. A nova geografia da produção de coco no Brasil. XI ENANPEGE, 2015, Pres. Prudente. Anais... Pres. Prudente: ENANPEGE, p. 2828-2839, 2015. Disponível em: www.enanpege.ggf.br/2015 (p. 2709-2720)

7. CAZELlA, Ademir. A.; BONNAL, Philippe.; MALUF, Renato. S. Agricultura familiar: multifuncionalidade e desenvolvimento territorial no Brasil. Rio De Janeiro: Mauad X, 2009.

8. COMISIÓN COMUNIDADES EUROPEAS. El futuro del mundo rural. Boletín de las CE. Suplemento $\mathrm{n}^{\circ} 4$, $1988.71 \mathrm{p}$.

9. CRUZ, Benedito Ely Valente da GOMES, Dérick Lima; CALVI, Miquéias Freitas. A agricultura camponesa no Marajó: entre o latifúndio tradicional e o moderno. XI ENANPEGE, 2015, Pres. Prudente. Anais... Pres. Prudente: ENANPEGE, p. 2828-2839, 2015. Disponível em: www. enanpege.ggf.br/2015. (p. 3115-3126). 
10. FRANZ, Juliana Cristina. Do sistema agrário colonial ao sistema agrário moderno: transformações sócio espaciais na agricultura familiar em Lajeado-RS. XI ENANPEGE, 2015, Pres. Prudente. Anais... Pres. Prudente: ENANPEGE, p. 2828-2839, 2015. Disponível em: www. enanpege.ggf.br/2015 (p. 2686-2697).

11. GRAZIANO DA SILVA, José. O novo rural brasileiro. Campinas, SP: UNICAMP. IE,1999.

12. KAGEYAMA, Angela A. Desenvolvimento Rural: conceitos e aplicação ao caso brasileiro.Porto Alegre: Ed. UFRGS, 2008.

13. LAMARCHE, Hughes (Org.). A Agricultura familiar: Do mito à realidade (Parte 2). Campinas: UNICAMP, 1998.

14. LOMBA, Roni Mayer; SUZUKI, Julio Cesar. Industrialização da agricultura e territorialização do capital: transformações recentes na relação campo-cidade em Caarapó - Mato Grosso do Sul - Brasil. XI ENANPEGE, 2015, Pres. Prudente. Anais... Pres. Prudente: ENANPEGE, p. 2828-2839, 2015. Disponível em: www.enanpege.ggf.br/2015 (p. 3152-3164)

15. NORDER, Luiz A.C. Mercantilização da agricultura e desenvolvimento territorial. In: SCHNEIDER, S. (Org.) A Diversidade da Agricultura Familiar. Porto Alegre: Ed. UFRGS, 2006. p.57-81.

16. OLIVEIRA, Ana Leticia de. As recentes transformações sócio espaciais do Noroeste MatoGrossense. XI ENANPEGE, 2015, Pres. Prudente. Anais... Pres. Prudente: ENANPEGE, p. 2828-2839, 2015. Disponível em: www.enanpege.ggf.br/2015 (p. 3089-3103)

17. PELISSON, Guilherme Valagna; DAVID, Cesar de. As sucessivas expansões das monoculturas de café, laranja e cana-de-açúcar do município de Tabapuã/SP e a resistência da agricultura familiar. XI ENANPEGE, 2015, Pres. Prudente. Anais... Pres. Prudente: ENANPEGE, p. 28282839, 2015. Disponível em: www.enanpege.ggf.br/2015 (p. 3037-3052)

18. SANTOS, Erika V. M.; LIMA, Maria do Socorro B. O rural no norte fluminense. XI ENANPEGE, 2015, Pres. Prudente. Anais ... Pres. Prudente: ENANPEGE, p. 2828-2839, 2015. Disponível em: www.enanpege.ggf.br/2015.

19. SANTOS, Milton. Por uma Outra Globalização. SP: Record, 2000.

20. SCHNEIDER, Sergio. Agricultura familiar e descentralização industrial. Porto Alegre: Editora da Universidade, 1999.

21. SILVA, Lilian Damares de Almeida; FONSECA, Ana Ivania Alves. Desenvolvimento rural no Brasil e no Norte de Minas: breves considerações. XI ENANPEGE, 2015, Pres. Prudente. Anais... Pres. Prudente: ENANPEGE, p. 2828-2839, 2015. Disponível em: www.enanpege.ggf. br/2015 (p. 2993-3001).

22. SILVA, Marcelo K.; MARQUES, Paulo E. M. Democratização e políticas públicas de desenvolvimento rural. In: SCHNEIDER, S.; SILVA,M.K.; MARQUES,P.E,M. (Orgs.) Políticas Públicas e Participação Social no Brasil Rural.Porto Alegre: Ed. UFRGS, 2009. p.9-20.

23. SODRÉ, Maiara Tavares. As transformações sócioespaciais no sistema agrário familiar de Pelotas/RS: a ação das políticas públicas na valorização da multifuncionalidade. XI ENANPEGE, 2015, Pres. Prudente. Anais ... Pres. Prudente: ENANPEGE, p. 2828-2839, 2015. Disponível em: www.enanpege.ggf.br/2015 (p. 2744-2755) 
24. SOUTO, Thales Silveira; BEZZI, Meri Lourdes. A pecuária leiteira em Ituiutaba/MG: perspectivas e entraves no desenvolvimento socioespacial do município. XI ENANPEGE, 2015, Pres. Prudente. Anais... Pres. Prudente: ENANPEGE, p. 2828-2839, 2015. Disponível em: www.enanpege.ggf.br/2015 (p. 2732-2743)

25. WANDERLEY, Maria N. B. Urbanização e ruralidades: relações entre a pequena cidade e o mundo rural. Estudo preliminar sobre os pequenos municípios em Pernambuco. In: WANDERLEY, M.N.B. O Mundo Rural como Espaço de Vida: reflexões sobre a propriedade da terra, agricultura familiar e ruralidade. Porto Alegre: Ed. da UFRGS, 2009. p.311-328.

26. YIN, R. K. Estudo de caso: planejamento e métodos. $2^{\text {a }}$ edição. Porto Alegre: Bookman, 2001. Artigo recebido em 2 de junho de 2016 Artigo aceito em 2 de julho de 2016 